\title{
Hepatitis B in Healthcare Workers: Prevalence, Vaccination and Relation to Occupational Factors
}

Luiz A.S. Ciorlia ${ }^{1}$ and Dirce M.T. Zanetta ${ }^{2}$

\author{
Occupational Medicine Service, Medical School of São José do Rio \\ Preto $^{1}$, Epidemiology and Public Health Department, Medical School \\ of São José do Rio Preto²; São José do Rio Preto, SP, Brazil
}

\begin{abstract}
The prevalence of hepatitis B virus (HBV) in healthcare workers (HCW) in Brazilian university hospitals is high. However, vaccination of these workers and relations with occupational factors are not well documented. A prospective study was made of 1,433 HCW and 872 administrative employees of the Hospital de Base (HB), São José do Rio Preto, SP, Brazil, and 2,583 blood donor candidates from the Hospital Blood Bank. HCW were observed from January 1994 to December 1999. Data were obtained from exams made when a worker entered hospital service, periodically and after work-related injuries. Serological reactions were analyzed in HCW who received HBV vaccine. Occupational and non-occupational information was obtained through a questionnaire. The prevalence of HBV among HCW $(\mathbf{0 . 8 \%})$ was significantly higher than in blood-donor candidates $(0.2 \%)$. Among the $\mathrm{HCW}$ who were vaccinated, $86.4 \%$ were immunized. Multivariate analysis revealed that increased age reduced the chance of immunization. Among the occupational factors, time in service contributed to a $14 \%$ increase in the chances of having positive serology, and work-related injuries increased the risk of HBV infection 4.29 times. The maximum risk sector presented a larger number of $\mathrm{HCW}$ with positive anti-HBc serology. There was a higher seroconversion in $\mathrm{HCW}$ who received the full set of $\mathrm{HBV}$ vaccines. In $\mathrm{HCW}$ with positive serology, the factors that presented greatest risks were time in service, work-related injuries and maximum risk sector.
\end{abstract}

Key Words: Hepatitis B, healthcare workers, prevalence, vaccination, occupational injuries.

Throughout the world, millions of healthcare professionals work in health institutions and it is estimated that 600,000 to 800,000 cut and puncture injuries occur among them per year, of which approximately $50 \%$ are not registered. In hospitals it is estimated that approximately 30 injuries occur per 100 beds per year[1]. Hepatitis B virus (HBV) is the greatest threat of infection for healthcare workers (HCW). The risk of contracting hepatitis B by healthcare personnel is four times greater than that of

Received on 10 June 2005; revised 23 September 2005.

Address for correspondence: Dr. Luiz Alberto de Souza Ciorlia. Rua Santo Agostinho 281. Zip code: 15025-220 - São José do Rio Preto, SP, Brazil. Phone: 1732222193.

E-mail: ciorliampo@yahoo.com.br

The Brazilian Journal of Infectious Diseases 2005;9(5):384-389 (C) 2005 by The Brazilian Journal of Infectious Diseases and Contexto Publishing. All rights reserved. the general adult population, among those who do not work in healthcare institutions [2].

The discovery of HBV vaccines and the results obtained from their introduction constitute a landmark of great importance for medical practice. Besides providing immunity against $\mathrm{HBV}$ infection, these vaccines indirectly protect against hepatocarcinoma [3]. During the last few years, the American Health Inspection Service has demonstrated a decrease in the incidence of hepatitis B in HCW, probably due to the use of vaccines and recommended safety measures [4].

Considering that hepatitis B virus is the etiological agent of chronic hepatopathies, and that patients with this acute infection may not develop symptoms in most cases, knowledge of aspects of this infection, such as prevalence, effectiveness of vaccination and relations to occupational exposure are fundamental for the 
improvement of preventive measures for health professionals.

Our objective was to determine the prevalence of HBV in HCW of a university hospital, to analyze HCW who had been vaccinated and their serological reactions, and to evaluate the risk factors for HCW with viral markers, and determine their epidemiological significance.

\section{Material and Methods}

The sample consisted of various professional categories working at the Hospital de Base (HB) of the Faculdade de Medicina de São José do Rio Preto (Famerp), São Paulo state, Brazil, a mediumsized hospital with 554 beds. From January 1994 to December 1999, 1547 healthcare professionals worked at the HB in three shifts. This group of HCW consisted of those who had direct contact with patients or who handled objects used by these patients, in disease diagnosis or auxiliary services. We did not include those who were on sick leave $(\mathrm{N}=11)$ and those who worked on the night shift $(\mathrm{N}=103)$; the total number of subjects in the study was 1433 HCW.

The group was subdivided into four groups, according to activities performed: 1- medical staff; 2- nursing (nurses, helpers, attendants and technical staff); 3- specialized technicians (X-ray, anesthesia and laboratory; biologists, biochemists, biomedical assistants, physiotherapists, perfusionists and occupational therapists), and 4- assistants and general services (radiology, laboratory, cleaning, operational services, laundry, blood bank and general services).

Two control groups were established to evaluate the prevalence of hepatitis B virus infection and to compare it to that observed in the HCW. The first group $(\mathrm{N}=872)$ consisted of staff personnel working in administration; they had no contact with the patients. The second group was made up of blood donor candidates $(\mathrm{N}=2583$ ) of the Blood Bank of the Fundação Faculdade Regional de Medicina de
São José do Rio Preto (Funfarme) in May 1999. The data regarding the HCW and administrative staff was compiled by the Occupational Therapy Service of the HB from admittance exams, periodical checkups, and reported work-related injuries.

Each sector was classified according to the risk of infection: maximum risk (hemodialysis, hemocenter, hemodynamics, blood bank, infectious diseases, emergency, laboratory, Intensive Care Unit and transplant unit), medium risk (internal medicine ward, surgery and pediatrics, material distribution, endoscopy, laundry (dirty laundry area), peritoneal dialysis and surgery room), and minimum risk (center of operations, graphics, cleaning and hygiene services, radiology, chemotherapy and trash collection).

Research was done using the enzyme immunoassay technique (ELISA) with HBsAg antigen and antibody serum (Hepanostika HBsAg UniForm II), anti-HBs (Hepanostika anti-HBs New) and anti-HBc (Hepanostika anti-HBc UniForm), all from Organon Lab (Boxtel, Netherlands); these were the serological markers of viral hepatitis B infection, in HCW and administration personnel.

Health staff with positive anti-HBs and anti-HBc results were considered immune (naturally-acquired immunity). Those with negative HbsAg, and/or separate negative anti-HBs or separate positive anti-HBc, were oriented to take the recombinant hepatitis B vaccine, Engerix B (SmithKline, Rixensart, Belgium), administered in triple doses of $20 \mu$ g each of the antigens by intramuscular injection in the deltoid region, with a one month interval between the first and second dose, and a five-month interval between the second and third dose (complete vaccination).

The collection of the second blood sample was done about a month after the third shot of the vaccine given to the HCW. This was done so that an evaluation of the seroconversion (research and quantification of antiHBs) could be made, considering as positive results those that were equal or superior to $10 \mathrm{IU} / \mathrm{L}$.

Work-related injuries were defined as those that occurred and were registered during working hours at the Hospital de Base, characterized by any percutaneous lesion with cutting or perforating objects, 
contact with biological material (blood, cerebrospinal fluid, amniotic and pleural fluids, urine or feces) on broken skin or mucus, and bites by patients.

In the case of work-related injuries, health professionals were submitted to hepatitis B serology on three separate occasions: on the date of the accident, six months and 12 months after exposure to biological material from known or unknown source-patients.

Four models that analyzed HBsAg dependent variables and positive anti-HBs and the work-related injuries with biological material were evaluated, using the odds ratio calculation (OR) adjusted with a confidence interval(CI). The significance probability was $\mathrm{p}<0.05$.

\section{Results}

The prevalence of viral hepatitis B (HBsAg) infection in HCW, administrative staff, and in blood donor candidates was recorded (Table 1). The HCW had significantly higher values than did blood-donor candidates $(\chi 2=7.65 ; \mathrm{p}<0.05)$.

Positive anti-HBc serological reaction was detected in the serum of $9.4 \%$ of HCW. Those with positive serology were significantly older than the ones who tested negative $(\mathrm{p}=0.031)$. The same occurred with the men in relation to the women ( $\mathrm{p}=0.046$; $\chi 2$ with Yates' correction. Health professionals who worked in the maximum risk sectors frequently had significantly higher positive serology than those who worked in other sectors ( $\chi 2$ test, $p=0.011$ ). Length of service, professional category, and the occurrence of an accident at work did not significantly influence the serology.

Serological tests (anti-HBs) were made after vaccination (Table 2). The association between vaccination and positive anti-HBs serology demonstrated that the chance of immunization among $\mathrm{HCW}$ is smaller with increasing age (multivariate analysis, OR = 0.978; CI 0.961-0.996; $\mathrm{p}=0.014$ ), the same occurring with men $(\mathrm{OR}=0.722$; $\mathrm{CI} 0.526$ 0.993; $\mathrm{p}=0.044$ ).

Among seropositive HBsAg health personnel, increases in time of service contributed towards increasing the chances of positive serology by $14 \%$ per year on the job (Multivariate analysis, $\mathrm{OR}=1.14$, CI 1.00-1.29, $\mathrm{p}=0.044)$. Work-related injuries increased the risk of infection by the hepatitis $\mathrm{B}$ virus 4.29 times in $\mathrm{HCW}(\mathrm{OR}=5.29$; $\mathrm{CI} 1.43-19.3$; $\mathrm{p}=$ 0.012).

Of the total number of HCW $(\mathrm{N}=1433)$ observed during the period of this study, 342 (23.9\%) were involved in registered work-related injuries with biological materials, furthermore, $21 \%$ of the sourcepatients had positive serology for HIV, HBsAg or antiHCV, $15.6 \%(\mathrm{~N}=71)$ tested negative and 63.4\% (N = 289) were unknown cases.

Hepatitis B serological results in HCW who had accidents and registered them on the date of the accident, identified $1.8 \%(\mathrm{~N}=6 / 342)$ cases of positive HBsAg. Serology performed in the follow-up 6 and 12 months later, gave the same results and there were no cases of infection serologically demonstrated during the period of this study.

\section{Discussion}

Studies on seroprevalence were made with HCW to assess the risk and frequency of blood borne diseases; we found that the prevalence of HBV is greater among HCW when compared to the general population. The prevalence found $(0.8 \%)$ was similar to findings in the literature [5-10], which also indicated that HBsAg is significantly more frequent in $\mathrm{HCW}$ when compared to blood donor candidates. In the hospital administration staff, which has no contact with patients, the prevalence of HBV infection was the same as for the blood donor candidates.

The hospital where the study was made is a university hospital, for tertiary and high complexity care. These factors make these HCW susceptible to a greater number of occurrences of HBV infection, which associated with the existence of asymptomatic HBsAg carriers in the general population, make it more difficult to assess the risk of viral infection in percutaneous accidents.

Positive anti-HBc serological reaction was found in the serum of $9.4 \%$ of HCW. Similar results were found 
Table 1. Prevalence of hepatitis B (HbsAg serology) and comparison between risk groups

\begin{tabular}{lccr}
\hline Groups & $\mathbf{N}$ & $\mathbf{N}$ & $\mathbf{( \% )}$ \\
\hline Healthcare personnel & 1,433 & $11 *$ & 0.8 \\
Administration personnel & 872 & 2 & 0.2 \\
Blood donor candidates & 2,583 & $5 *$ & 0.2 \\
Total & 4,888 & 18 & 0.4 \\
\hline N = number of individuals; $n$ = individuals with positive HBsAg serology. * $\mathrm{p}<0.05, \chi^{2}$ test.
\end{tabular}

Table 2. Distribution of positive anti-HBs serology frequency in healthcare workers, according to vaccination status

\begin{tabular}{lccc}
\hline Vaccination & $\mathbf{N}$ & $\mathbf{N}$ & $\mathbf{( \% )}$ \\
\hline Not vaccinated & 243 & 47 & 19.3 \\
Incomplete & 137 & 80 & 58.4 \\
Complete & 1,053 & 910 & 86.4 \\
Total & 1,433 & 1037 & 72.4 \\
\hline $\mathrm{N}$ = number of healthcare workers; $\mathrm{n}$ = healthcare workers with positive anti-HBs serology.
\end{tabular}

by Uip et al. [11] - 10.4\%, Coelho et al. [12] - 9.7\% and Fernandes et al. [13] - 8.1\%. The frequency was markedly greater in HCW who were significantly older and in the maximum risk sector. The serological profile may be associated with the time on the job. Contact with $\mathrm{HBV}$ is probably due to occupational exposure, especially in high-risk sectors, such as hemodyalisis, emergency, blood bank, etc.

A study carried out during an outbreak of HBV hospital infection made it clear that the HCW who had surface antibodies against the virus were protected [14]. Beginning in 1982, hepatitis B vaccine was evaluated in various studies, demonstrating its efficiency [15]. Since HCW have a greater probability of acquiring this infection, because they are occupationally exposed, the need for vaccination against this disease should be considered a priority.

The hepatitis B vaccination program at the Hospital de Base enabled the application of the complete set of vaccines to $73.5 \%$ of the HCW. The result, when compared with those of Costa et al. [16] - 39.3\% and Luz et al. [17] - 58.9\%, demonstrates that the vaccination program was successful. This may also be attributed to the previous explanations on the risks and efficiency of the vaccine being used. These vaccination percentage results were similar to those of studies performed in 232 American hospitals, of which 75\% had a vaccination program and $77 \%$ initially paid for the vaccination of high risk HCW and later did the same for all who were exposed [18]. The best rate of compliance occurred in hospitals that paid for the vaccine and made vaccination mandatory. This attitude was adopted in our investigation. The post-vaccine serological test is recommended for all who work in clinical environments and depend on being immunized. Anti-HBs serology was performed on all HCW who were vaccinated. Of those who received the full vaccination, $86.4 \%$ tested positive, that is they were 
immunized against HBV infection, emphasizing the efficiency and importance of this vaccine. Almost 20\% of those who were not vaccinated had already acquired natural immunity through previous contact with HBV, and probably if they continued to be exposed, though at a low intensity, this would mean that they would acquire increased immunization instead of infection. These results were similar to those of Lanphear et al. [19]. Among HCW with positive anti-HBs serology, immunization decreased with increasing age. Krugman \& Stevens [20] found the same results in those who were over 40 years old. Positive HBsAg serology was associated with extended time in service, as also reported by Coelho [12] and Janzen et al. [21].

Handling material contaminated with blood or secretion is intrinsic to HCW activities. The main problem, however, is that these professionals often handle the material incorrectly, increasing the risk of accidents. In this study, 456 reported accidents with biological materials occurred and source-patient serology tested $21 \%$ positive for the HIV, HBV or HCV pathogens, thus increasing the risk of blood-borne pathogen transmission. This frequency was relatively higher when compared to that found by Kelen et al. [22] and Lanphear et al. [23], but lower than that found by Marino et al. [24].

The serological follow-up performed on the HCW who suffered accidents was complemented, in all cases, with a follow-up during at least one year after exposure. Although the recommended time for follow-up is six months, in this research the period was increased to one year, because there are cases described in the medical literature of antibodies detected after six months, indicating late seroconversion, as noted by Gerberding et al. [25].

Among the reported accidents, there were no cases of hepatitis B seroconversion. The same result was found by Baldo et al. [26]. Although there were no cases of seroconversion registered during this study, work-related accidents were associated with HCW who presented positive serology. This association was relevant because of frequent occupational exposure. This finding confirms the conclusions made by Dienstag et al. [27] and Hadler et al. [28].
With regards to HBV infection, efforts have been focused on reducing the occurrence of exposure to blood and body fluids. These strategies include reevaluating the kind of material used, demanding strict compliance for protection in risky occupational procedures, the use of gloves and other barriers and a follow-up with serological tests whenever there is a case of work-related injury with biological material, as well as mandatory vaccination and treatment after exposure.

Making the risks of HBV infection known, as well as knowledge on the serology and need for preventive measures (universal precaution and vaccination) are fundamental factors to protect HCW against this disease.

\section{References}

1. EPINET [1999]. Needlestick prevention devices. Health Devices 1999;28:381-407.

2. Byrne E.B. Viral hepatitis: on occupational hazard of medical personnel. Experience of the Yale-New Haven Hospital, 1952-1965. JAMA 1966;195:362-4.

3. Beasley RP. Hepatitis B immunization strategies: expanded programme of immunization. World Health Organization; 1988. 26p.

4. CDC. Guideline for Infection Control in Healthcare Personnel. Infect Control Hosp Epidemiol 1998;19:407-63.

5. Gerberding J.L., Bryant-LeBlanc C.E., Nelson K., et al. Risk of transmitting the human immunodeficiency virus, cytomegalovirus, and hepatitis B virus to healthcare workers exposed to patients with AIDS and AIDSrelated conditions. J Infect Dis 1987;156(1):1-8.

6. Short L.J., Bell D.M. Risk of occupational infection with blood borne pathogens in operating and delivery room settings. Am J Infect Control 1993;6:343-50.

7. Focaccia R., Veronesi R., Takeda A.K., et al.. Risco de contágio pelo vírus da hepatite $\mathrm{B}$ em funcionários hospitalares e imunidade naturalmente adquirida. AMB Rev Assoc Med Bras 1986;32:111-4.

8. Willy M.E., Dhillon G.L., Loewen N.L., et al. Advance exposures and universal precautions practiced among a group of highly exposed health professionals. Infect Control Hosp Epidemiol 1990;11:352-6.

9. Reed E., Daya M.R., Jui J., et al. Occupational infectious disease exposures in SEM personnel. J Emerg Med 1993;11:9-16. 
10. Weiss Y., Rabinovitch M., Cahner Y., et al. Prevalence of hepatitis B virus markers among hospital personnel in Israel: correlation with some risk factors. J Hosp Infect 1994;26:211-8.

11. Uip D.E., Amato U.S., Amato Neto V., et al. Avaliação sorológica para o vírus da imunodeficiência humana (HIV) e da hepatite B (HBV) nos candidatos aprovados em exame admissional de instituição hospitalar de São Paulo. Rev Assoc Med Bras 1995;41:141-3.

12. Coelho H.S.M., Artemenko S.R.T., Martins C.N., et al. Prevalência da infecção pelo vírus B na comunidade hospitalar. Rev Soc Bras Med Trop 1990;23:71-6.

13. Fernandes J.V., Braz R.F.S., Neto F.V.A., et al. Prevalência de marcadores sorológicos do vírus da hepatite $\mathrm{B}$ em trabalhadores do serviço hospitalar. Rev Saúde Públ 1999;33:122-8.

14. Snydman D.R., Bryan J.A., London W.T., et al. Hemodialysis associated hepatitis: report of an epidemic with further evidence on mechanisms of transmission. Am J Epidemiol 1976;134:562-70.

15. CDC. Protection against viral hepatitis: recommendations of the Immunizations Practices Advisory Committee. MMWR 1990;39(RR-2):1-26.

16. Costa J.M., Comaru Pasqualotto A., Mendoza Segat F., et al. Hepatitis B vaccination of healthcare workers is not yet a reality. Braz J Infect Dis 1997;1:248-55.

17. Luz C.E., Knudsen S.I., Pitol R., et al. Hepatite B: prevenção inadequada até em profissionais da área da saúde. Rev Bras Med 2000;57:144-51.

18. Alexander P.G., Johnson R., Williams W.N., et al. Hepatitis $B$ vaccination programs for healthcare personnel in US hospitals. Public Health Rep 1990;105:610-6.

19. Lanphear B.P., Linnemann Jr. C.C., Cannon C.G., De Ronde M.M. Decline of clinical hepatitis B in workers at a general hospital: relation to increasing vaccine-induced immunity. Clin Infect Dis 1993;16:10-4.

20. Krugman S., Stevens C.E. Hepatitis B vaccine. In: Plotkin SA, Mortimer Jr EA, eds. Vaccines. $2^{\text {nd }}$ ed. Philadelphia: WB Saunders, 1994: 419-37.

21. Janzen J., Tripatzis I., Wagner U., et al. Epidemiology of hepatitis B surface antigen (HBsAg) and antibody to HBsAg in hospital personnel. J Infect Dis 1978;137:261-5.

22. Kelen G.D., Green G.B., Purcell R.H., et al. Hepatitis B and hepatitis C in emergency department patients. N Engl J Med 1992;326:1399-404.

23. Lanphear B.P., Linnemann Jr. C.C., Cannon C.G., et al. Hepatitis $C$ virus infection in healthcare workers: risk of exposure and infection. Infect Control Hosp Epidemiol 1994;15:745-50.

24. Marino C.G.G., El-Far F., Wey S.B., Medeiros E.A.S. Cut and puncture accidents involving healthcare workers exposed to biological materials. Braz J Infect Dis 2001;5:235-42.
25. Gerberding J.L., Henderson D.K. Management of occupational exposures to bloodborne pathogens: hepatitis B virus, hepatitis C virus, and human immunodeficiency virus. Clin Infect Dis 1992;14:1179-85.

26. Baldo V., Floreani A., Dal Vecchio L., et al. Occupational risk of blood-borne viruses in healthcare workers: a 5year surveillance program. Infect Control Hosp Epidemiol 2002;23:325-7.

27. Dienstag J.L., Ryan D.M. Occupational exposure to hepatitis B virus in hospital personnel. Infection or immunization ? Am J Epidemiol 1982;115:26-39.

28. Hadler S.C., Doto I.L., Maynard J.E., et al. Occupational risk of hepatitis B infection in hospital workers. Infect Control 1986;6:24-31. 